\title{
Impacts of $\mathrm{C}_{60}$-Ionic Liquids (ILs) Interactions and IL Alkyl Chain Length on $\mathbf{C}_{60}$ Dispersion Behavior: Insights at the Molecular Level
}

\author{
Zhuang Wang, ${ }^{*}$ Lili Tang, ${ }^{\dagger}$ and Degao Wang ${ }^{\ddagger}$ \\ Jiangsu Key Laboratory of Atmospheric Environment Monitoring and Pollution Control (AEMPC), School of Environmental \\ Science and Engineering, Nanjing University of Information Science and Technology, Nanjing 210044, P.R. China \\ "E-mail: zhuang.wang@nuist.edu.cn \\ ${ }^{\dagger}$ Jiangsu Environmental Monitoring Centre, Nanjing 210036, P.R. China \\ :Department of Environmental Science and Engineering, Dalian Maritime University, Dalian, 116026, P.R. China \\ Received February 16, 2014, Accepted May 11, 2014
}

\begin{abstract}
Mechanisms underlying the impacts of interactions between carbon nanoparticles (CNPs) and ionic liquids (ILs) on the physicochemical behavior of CNPs need to be more full worked out. This manuscript describes a theoretical investigation at multiple levels on the interactions of fullerene $\mathrm{C}_{60}$ with 21 imidazolium-based ILs of varying alkyl side chain lengths and anionic types and their impacts on $\mathrm{C}_{60}$ dispersion behavior. Results show that $\pi$-cation interaction contributed to mechanism of the $\mathrm{C}_{60} \mathrm{IL}$ interaction more than $\pi$-anion interaction. The calculated interaction energy $\left(E_{\mathrm{INT}}\right)$ indicates that $\mathrm{C}_{60}$ can form stable complex with each IL molecule. Moreover, the direction of charge transfer occurred from IL to $\mathrm{C}_{60}$ during the $\mathrm{C}_{60} \mathrm{IL}$ interaction. Quantitative models were developed to evaluate the self-diffusion coefficient of $\mathrm{C}_{60}\left(D_{\text {fullerene }}\right)$ in bulk ILs. Three interpretative molecular descriptors (heat of formation, $E_{\mathrm{INT}}$, and charge) that describe the $\mathrm{C}_{60}-\mathrm{IL}$ interactions and the alkyl side chain length were found to be determinants affecting $D_{\text {fullerene. }}$
\end{abstract}

Key Words : Fullerene, Ionic liquids, Interaction, Dispersion, Molecular modeling

\section{Introduction}

Carbon nanoparticles (CNPs) which are likely to be released to the environment as the result of a variety of human-related sources (release from polymeric products and/or direct discharge to surface water, etc.) move across environmental boundaries, and may thus end up in most media..$^{1-3}$ To appropriately evaluate the potential environmental risks posed by CNPs, it is crucial to understand critical physicochemical processes affecting the behavior of CNPs after release. ${ }^{4,5}$ Physicochemical interactions are of particular concern, as CNPs with high surface reactivity can interact with a variety of compounds in the aquatic environment, such as natural organic matter, ${ }^{6,7}$ surfactants, ${ }^{8,9}$ and environmentally relevant organic acids. ${ }^{10}$ Numerous studies have attempted to address the effects of these interactions on the surface properties, ${ }^{11}$ aggregation/deposition ${ }^{12}$ and dispersion behavior, ${ }^{13}$ as well as ecotoxicities of CNPs. ${ }^{14}$

Ionic liquids (ILs) are a new class of organic salts that are composed solely of cations and anions. ${ }^{15}$ ILs can promise enormous potential for industrial applications, due to their unusual low melting temperature, relatively low viscosity, negligible vapor pressure, as well as high thermal and chemical stability. ${ }^{16}$ Moreover, contemporary studies indicate that their "greenness" depends strongly on their structures, ${ }^{17}$ and that these intrinsic properties also make ILs superior as ideal dispersing media for CNPs. ${ }^{18-20}$ Accordingly, it is presently unclear whether CNPs produced in the presence of ILs will directly correspond to CNP-IL complexes that will be found in the environment. Furthermore, though there is no direct evidence for ILs being found in the environment, recent efforts to prepare for possible release suggest that ILs can present a low to high risk to human and ecological species. ${ }^{16,21,22}$ However, very little information is available on the impacts of CNP-IL interactions on the physicochemical behavior of CNPs. This is due to the fact that experimental data about the interactions between CNPs and ILs are not readily available, and the mechanisms underlying the interactions need to be more full worked out. Therefore, we should start by focusing on the particular interaction when the combined exposure to CNPs and ILs is being evaluated.

Experimental testing for the physicochemical interactions of CNPs can be laborious, costly, and time-consuming. Current computational methods such as molecular modeling has emerged in recent years as an important compliment to experiment for delivering useful information on molecular properties and providing an insight to the interaction mechanisms of CNPs with other compounds from the environment. ${ }^{23-26}$ Because of its well-defined structure, $\mathrm{C}_{60}$ was frequently chosen as a representative CNP in computational studies assessing the physicochemical interactions of CNPs. ${ }^{24,25}$ It was the purpose of this study to investigate the interactions between $\mathrm{C}_{60}$ and 21 imidazolium-based ILs containing various alkyl side chain lengths and anionic types by molecular modeling. Optimum molecular geometry corresponding to the strongest binding of $\mathrm{C}_{60}$ with each IL was assessed by molecular mechanics (MM) simulations. The radial distribution function (RDF) $\mathrm{g}(r)$ of the selected atoms of the IL-cation or anion to the centre of mass of $\mathrm{C}_{60}$ was calculated to understand the interaction mechanism. Quantum 
mechanics (QM) approaches were devoted to the estimation of heat of formation $(H F)$ and interaction energy $\left(E_{\mathrm{INT}}\right)$ of $\mathrm{C}_{60}$ with ILs, which were utilized to evaluate the formation and stability of the IL- $\mathrm{C}_{60}$ complexes, respectively. Charge transfer was elucidated during the $\mathrm{C}_{60}$-IL interaction. Later, we also described the microscopic dispersion process of $\mathrm{C}_{60}$ agglomerates in bulk ILs by large-scale molecular dynamics (MD) simulations. On the basis of the mechanism understanding, linear regression models for the quantitative assessment of the self-diffusion coefficient of $\mathrm{C}_{60}$ ( $\left.D_{\text {fullerene }}\right)$ in bulk ILs consisting of quantum chemical parameters and number of carbon atoms in the alkyl chain $\left(n_{\mathrm{C}}\right)$ were developed using partial least squares (PLS) technique.

\section{Computational Methods}

Theoretical Methods. In this study, seven homologues of imidazolium-based ILs $\left(\left[\mathrm{C}_{\mathrm{n}} \mathrm{mim}\right]^{+}\right)$paired to three different anions (tetrafluoroborate $\left[\mathrm{BF}_{4}\right]^{-}$, chloride $[\mathrm{Cl}]^{-}$, and hexafluorophosphate $\left[\mathrm{PF}_{6}\right]^{-}$) were selected as model molecules (Figure 1). To find the best geometry for each $\mathrm{C}_{60}-\mathrm{IL}$ complex, a classical annealing simulation was carried out using the Forcite Plus code. ${ }^{27}$ The universal force field was adopted to perform this simulation. The cutoff radius was chosen to be $18.5 \AA$. The annealing simulation was carried out as follows: a total of 200 annealing cycles was simulated with an initial (mid cycle) temperature of $200 \mathrm{~K}(300 \mathrm{~K})$ and 50 heating ramps per cycle, with 100 dynamic steps per ramp. The canonical ensemble (NVT) was used, and the molecular dynamics were performed with a time step of 1.0 fs and a Nose' thermostat. After each cycle, the lowest energy configuration was optimized. The atomic configuration with the lowest total energy for each $\mathrm{C}_{60}$-IL complex was built as a set of inputs for the calculations of quantum chemical properties. Meanwhile, the annealing simulation was also carried out in a $20 \AA \times 20 \AA \times 20 \AA$ unit cell consisting of each optimized $\mathrm{C}_{60}$-IL complex for the $\mathrm{RDF}$ calculations.

The quantum chemical calculations of $H F$ and total energy $\left(E_{\mathrm{T}}\right)$ have been carried out at the semi-empirical level of the theory with use of MOPAC-PM3 method in the ChemOffice software (Ver. 11.0). Semi-empirical methods are usually much faster with the comparison of ab initio and density

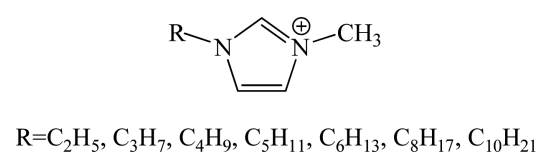

(a)<smiles>F[B-](F)(F)F</smiles>

(b)

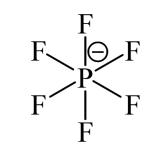

(d)
Figure 1. Schematic diagram showing the ionic liquids (ILs) studied in this work. Cations: (a) seven homologues of imidazoliumbased ILs; Anions: (b) tetrafluoroborate, (c) chloride, and (d) hexafluorophosphate. functional theory calculations, enable to perform calculations for larger systems. ${ }^{28}$ Mulliken population analysis as a probe of elucidating charge transfer during the $\mathrm{C}_{60}$-IL interaction was performed at the same level of theory on the optimized structures.

The bulk ILs and $\mathrm{C}_{60}$-IL dispersions were molded using full atomistic MD simulations in NVT ensemble using the universal force field, ${ }^{18}$ subjected to periodic boundary conditions in all three directions. The IL bulk phase consisted of 250 pairs of IL-cations and IL-anions in a $45 \AA \times 45 \AA \times 45 \AA$ unit cell. The initial configuration of the $\mathrm{C}_{60}$-IL system consisted of an agglomerate species of $\mathrm{C}_{60}$ and the IL phase. Our MD simulations were performed at the temperature of 298 K. A simulation step of 100,000 was carried out to relax the system into equilibrium at a time step of $0.1 \mathrm{fs}$ and the final one $10 \mathrm{ps}$ for production. As shown in Figure S1 (Supplementary data), the system has already achieved equilibrium after the simulation time. MD simulations have been carried out using Material Explorer 5.0 program.

Radial Distribution Function Calculation and Interaction Energy. RDF that indicates the density change of microscopic atoms or molecules as function of the distance from one particular atom or molecule was employed to elucidate the feature of the $\mathrm{C}_{60}$-IL interaction. RDF was calculated by:

$$
g(r)=\frac{\mathrm{d} N}{\rho 4 \pi r^{2}}
$$

where $g(r)$ is the RDF, $\mathrm{d} N$ is the number of atoms or molecules at a distance between $r$ and $r+\mathrm{d} r$ from a given target atom or molecule, $\rho$ is the density of the studied system.

$E_{\mathrm{INT}}$ was used to evaluate the stability of the $\mathrm{C}_{60}-\mathrm{IL}$ complexes. The magnitude of $E_{\mathrm{INT}}$ is an indication of the magnitude of the driving force towards complexation. The more negative the $E_{\mathrm{INT}}$ value, the more thermodynamically favorable the inclusion complex is. $E_{\mathrm{INT}}$ was calculated as follows:

$$
E_{\mathrm{INT}}=E_{\mathrm{T}}\left(\mathrm{C}_{60}+\mathrm{IL}\right)-E_{\mathrm{T}}\left(\mathrm{C}_{60}\right)-E_{\mathrm{T}}(\mathrm{IL})
$$

where $E_{\mathrm{T}}\left(\mathrm{C}_{60}+\mathrm{IL}\right), E_{\mathrm{T}}\left(\mathrm{C}_{60}\right)$, and $E_{\mathrm{T}}(\mathrm{IL})$ represent the optimized $E_{\mathrm{T}}$ of the complex, the isolated $\mathrm{C}_{60}$, and the IL molecules, respectively.

Mean Square Displacement and Self-diffusion Coefficient. The mean square displacement (MSD) that describes the average displacement of an atom during a fixed time $t$, was employed to characterize the dispersion process of $\mathrm{C}_{60}$ in the bulk ILs. The MSD for $\mathrm{C}_{60}$ in the bulk ILs was calculated by preparing several time series data items of Length $t$, averaging those data items, and averaging those data items based on the number of atoms $(N)$, then MSD is defined as follows:

$$
M S D=\left\langle|r(t)-r(0)|^{2}\right\rangle=\frac{1}{N M} \sum_{i}^{N} \sum_{k}^{M}\left|r_{i}\left(t_{k}+t\right)-r_{i}\left(t_{k}\right)\right|^{2}
$$

where $M$ is the number of time series data, and $t_{\mathrm{k}}$ is the starting time of $k$-th time series data. The $D_{\text {fullerene value was }}$ calculated using Einstein's equation: 


$$
D_{\text {fullerene }}=\frac{1}{6 t} M S D
$$

The PLS regression was performed with XLSTAT (Ver. 2013.5.03) to construct quantitative models.

\section{Results and Discussion}

Features of Interactions between $\mathbf{C}_{60}$ and ILs. The optimized conformations obtained after the annealing simulation are shown in Figure S2 (Supplementary data). The optimized geometries for ILs adsorbed onto the surface of $\mathrm{C}_{60}$ indicate that the IL-cation has a stronger affinity than its anionic partner. Maciel et al. also found that in $\left[\mathrm{C}_{4} \mathrm{mim}\right]\left[\mathrm{BF}_{4}\right]$ the IL-cation nears the surface of $\mathrm{C}_{60}$ described using an extensive MD simulation. ${ }^{20}$ To make insight into the structure of ILs around the $\mathrm{C}_{60}$ more deeply, the RDF profiles of nitrogen-2 atom in $\left[\mathrm{C}_{\mathrm{n}} \mathrm{mim}\right]^{+}$, boron atom in $\left[\mathrm{BF}_{4}\right]^{-}$, chloride atom in $[\mathrm{Cl}]^{-}$, phosphorus atom in $\left[\mathrm{PF}_{6}\right]^{-}$relative to the centre of mass of $\mathrm{C}_{60}$ were characterized (Fig. S3-S5, Supplementary data). The radius of $\mathrm{C}_{60}(-3.49 \AA)$ is marked in Figure S3-S5 to indicate the distance between the selected atoms of ILs and the approximate spherical surface of $\mathrm{C}_{60}$. There is an obvious peak near the $\mathrm{C}_{60}$ surface in each RDF curve for the both selected atoms of ILs relative to the $\mathrm{C}_{60}$ centroid. This means that there are $\pi$-cation and $\pi$-anion interactions between $\mathrm{C}_{60}$ and ILs. For all the 21 ILs studied, it was observed that the RDF peaks for the IL-cations were higher than those for the IL-anions, indicating that the ILcations have stronger interactions with $\mathrm{C}_{60}$ than the IL-anions. This also suggests that the $\pi$-cation interaction contributes more to mechanism of the $\mathrm{C}_{60}$-IL interaction, compared with the $\pi$-anion interaction. Gao et al. also found that $\pi$-cation interaction can play a dominated role in the dispersion of multi-walled carbon nanotubes (CNTs) by in a IL-based polyether in aqueous solutions. ${ }^{19}$ As $\mathrm{C}_{60}$ is non-polar, and ILs are polar molecules, the van der Waals interactions that are mainly dispersion and induction interactions also contribute to the mechanism in CNP-IL interactions. ${ }^{24}$

The estimated quantum parameters for the $\mathrm{C}_{60}$-IL complexes are presented in Table 1. For the $\mathrm{C}_{60}-\left[\mathrm{C}_{\mathrm{n}} \mathrm{mim}\right]\left[\mathrm{BF}_{4}\right]$ complexes, the calculated $H F$ values are negative, indicating that the formation of the complexes is exothermic. For the $\mathrm{C}_{60}-\left[\mathrm{C}_{\mathrm{n}} \mathrm{mim}\right][\mathrm{Cl}]$ and $\mathrm{C}_{60}-\left[\mathrm{C}_{\mathrm{n}} \mathrm{mim}\right]\left[\mathrm{PF}_{6}\right]$ complexes, the calculated $H F$ values are positive, indicating that the formation of the complexes is endothermic. In general, the $H F$ values decrease with an increase of the alkyl side chain length on the imidazolium ring. The calculated $E_{\mathrm{INT}}$ values are negative, indicating that $\mathrm{C}_{60}$ can form stable complexes with ILs. Generally, the alkyl side chain length on the imidazolium ring has no significant impacts on $E_{\mathrm{INT}}$ for the $\mathrm{C}_{60}$-IL interactions. However, such cations of the general formula $\left[\mathrm{C}_{\mathrm{n}} \mathrm{mim}\right]^{+}$studied contain both a symmetry-breaking region $\left(n_{\mathrm{C}}<7\right)$ and hydrophobic region..$^{29}$ Moreover, CNPs exhibit extreme hydrophobicity. ${ }^{30}$ Our previous study also indicates that hydrophobic interaction can provide a partial contribution to the mechanism for the $\mathrm{C}_{60}$-IL interaction. ${ }^{31}$ According to the Mulliken population
Table 1. Estimated quantum parameters for the $\mathrm{C}_{60}$-IL complexes

\begin{tabular}{|c|c|c|c|}
\hline & $\begin{array}{c}\text { Heat of } \\
\text { formation } \\
(\mathrm{kcal} / \mathrm{mol})\end{array}$ & $\begin{array}{l}\text { Interaction } \\
\text { energies } \\
(\mathrm{kcal} / \mathrm{mol})\end{array}$ & $\begin{array}{c}\text { Mulliken } \\
\text { Charges }\left(\mathrm{C}_{60}\right) \\
q(\mathrm{e})\end{array}$ \\
\hline$\left[\mathrm{C}_{2} \mathrm{mim}\right]\left[\mathrm{BF}_{4}\right]$ & -397.1 & -10.3 & -0.0013 \\
\hline$\left[\mathrm{C}_{3} \operatorname{mim}\right]\left[\mathrm{BF}_{4}\right]$ & -401.5 & -5.3 & -0.0009 \\
\hline$\left[\mathrm{C}_{4} \mathrm{mim}\right]\left[\mathrm{BF}_{4}\right]$ & -410.2 & -6.2 & -0.0011 \\
\hline$\left[\mathrm{C}_{5} \mathrm{mim}\right]\left[\mathrm{BF}_{4}\right]$ & -412.8 & -6.8 & -0.0010 \\
\hline$\left[\mathrm{C}_{6} \mathrm{mim}\right]\left[\mathrm{BF}_{4}\right]$ & -417.7 & -6.7 & -0.0015 \\
\hline$\left[\mathrm{C}_{8} \mathrm{mim}\right]\left[\mathrm{BF}_{4}\right]$ & -429.2 & -9.7 & -0.0032 \\
\hline$\left[\mathrm{C}_{10} \mathrm{mim}\right]\left[\mathrm{BF}_{4}\right]$ & -439.9 & -4.3 & -0.0013 \\
\hline$\left[\mathrm{C}_{2} \mathrm{mim}\right][\mathrm{Cl}]$ & 796.1 & -3.4 & -0.0003 \\
\hline$\left[\mathrm{C}_{3} \operatorname{mim}\right][\mathrm{Cl}]$ & 789.4 & -2.3 & -0.0010 \\
\hline$\left[\mathrm{C}_{4} \mathrm{mim}\right][\mathrm{Cl}]$ & 787.5 & -5.5 & -0.0015 \\
\hline$\left[\mathrm{C}_{5} \mathrm{mim}\right][\mathrm{Cl}]$ & 775.3 & 0.5 & -0.0006 \\
\hline$\left[\mathrm{C}_{6} \mathrm{mim}\right][\mathrm{Cl}]$ & 775.9 & -4.8 & -0.0018 \\
\hline$\left[\mathrm{C}_{8} \mathrm{mim}\right][\mathrm{Cl}]$ & 763.0 & -2.2 & -0.0003 \\
\hline$\left[\mathrm{C}_{10} \mathrm{mim}\right][\mathrm{Cl}]$ & 754.0 & -4.0 & -0.0006 \\
\hline$\left[\mathrm{C}_{2} \mathrm{mim}\right]\left[\mathrm{PF}_{6}\right]$ & 357.5 & -0.1 & -0.00004 \\
\hline$\left[\mathrm{C}_{3} \operatorname{mim}\right]\left[\mathrm{PF}_{6}\right]$ & 380.4 & -27.6 & -0.0016 \\
\hline$\left[\mathrm{C}_{4} \mathrm{mim}\right]\left[\mathrm{PF}_{6}\right]$ & 346.5 & -2.9 & -0.0004 \\
\hline$\left[\mathrm{C}_{5} \mathrm{mim}\right]\left[\mathrm{PF}_{6}\right]$ & 343.1 & -1.7 & -0.0006 \\
\hline$\left[\mathrm{C}_{6} \mathrm{mim}\right]\left[\mathrm{PF}_{6}\right]$ & 363.9 & -28.3 & -0.0009 \\
\hline$\left[\mathrm{C}_{8} \operatorname{mim}\right]\left[\mathrm{PF}_{6}\right]$ & 325.8 & -1.1 & -0.0006 \\
\hline$\left[\mathrm{C}_{10} \mathrm{mim}\right]\left[\mathrm{PF}_{6}\right]$ & 314.7 & -1.2 & -0.0006 \\
\hline
\end{tabular}

analysis, $\mathrm{C}_{60}$ has negative charges $(q)$, implying that charge transfer occurred from IL to $\mathrm{C}_{60}$ during the $\mathrm{C}_{60}$-IL interaction, as indicated in Table 1. The results of Wagle et al. also suggested that the direction of charge transfer determined from a Mulliken population analysis is from IL to polyaromatic hydrocarbons (as precursors of $\mathrm{C}_{60}$ ). ${ }^{32}$ In addition, it is noticeable that a weak correlation exists between the degree of charge transfer and the alkyl side chain length attached to the imidazolium ring.

Impacts of IL Alkyl Chain Length and $\mathrm{C}_{60}$-IL Interactions on $\mathbf{C}_{60}$ Dispersion in Bulk ILs. $\mathrm{C}_{60}$-IL dispersions have been investigated by means of full atomistic MD simulations. Figure S6 (Supplementary data) presents snapshots corresponding to the dispersion state and spatial distribution of $\mathrm{C}_{60}$ agglomerates in the different bulk ILs after 100,000 simulation steps. Though different dispersion extent can be obtained in the different bulk ILs, in general, $\mathrm{C}_{60}$ can be effectively dispersed in the bulk ILs. As discussed above, there are special interactions such as $\pi$-cation and hydrophobic interaction between $\mathrm{C}_{60}$ and ILs. When $\mathrm{C}_{60}$ are ground with ILs, the strong $\pi-\pi$ interaction between $\mathrm{C}_{60}$ is shielded by ILs. Then these special interactions could be the driving force that disperses $\mathrm{C}_{60}$ in the bulk ILs. Experimental studies of Wang et al. also suggest that ILs finely disperse singlewalled CNTs by shielding a strong stacking interaction among CNPs. ${ }^{18}$

The evolution of the MSD of each system with the simulation time was shown in Figure S7 (Supplementary data). Furthermore, the number of carbon atoms in the alkyl chain of ILs is varied to probe its effects on the $\mathrm{C}_{60}$ dispersion state 
(Figure 2). For the $\left[\mathrm{BF}_{4}\right]^{-}$analog, the dispersion extent ( $\left.D_{\text {fullerene }}\right)$ increases with an increase of the alkyl side chain length attached to the imidazolium ring. However, it is noted that, with a further increase of the alkyl side chain length, the dispersion extent of $\mathrm{C}_{60}$ decreases. This observation also implies that a good dispersion can be obtained by the presence of $\left[\mathrm{C}_{4} \mathrm{mim}\right]\left[\mathrm{BF}_{4}\right]$. Generally, for the $[\mathrm{Cl}]^{-}$and $\left[\mathrm{PF}_{6}\right]^{-}$ analogs the increase in the alkyl side chain length decreases

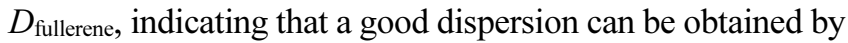
the presence of short alkyl side chain. Note that IL contain-
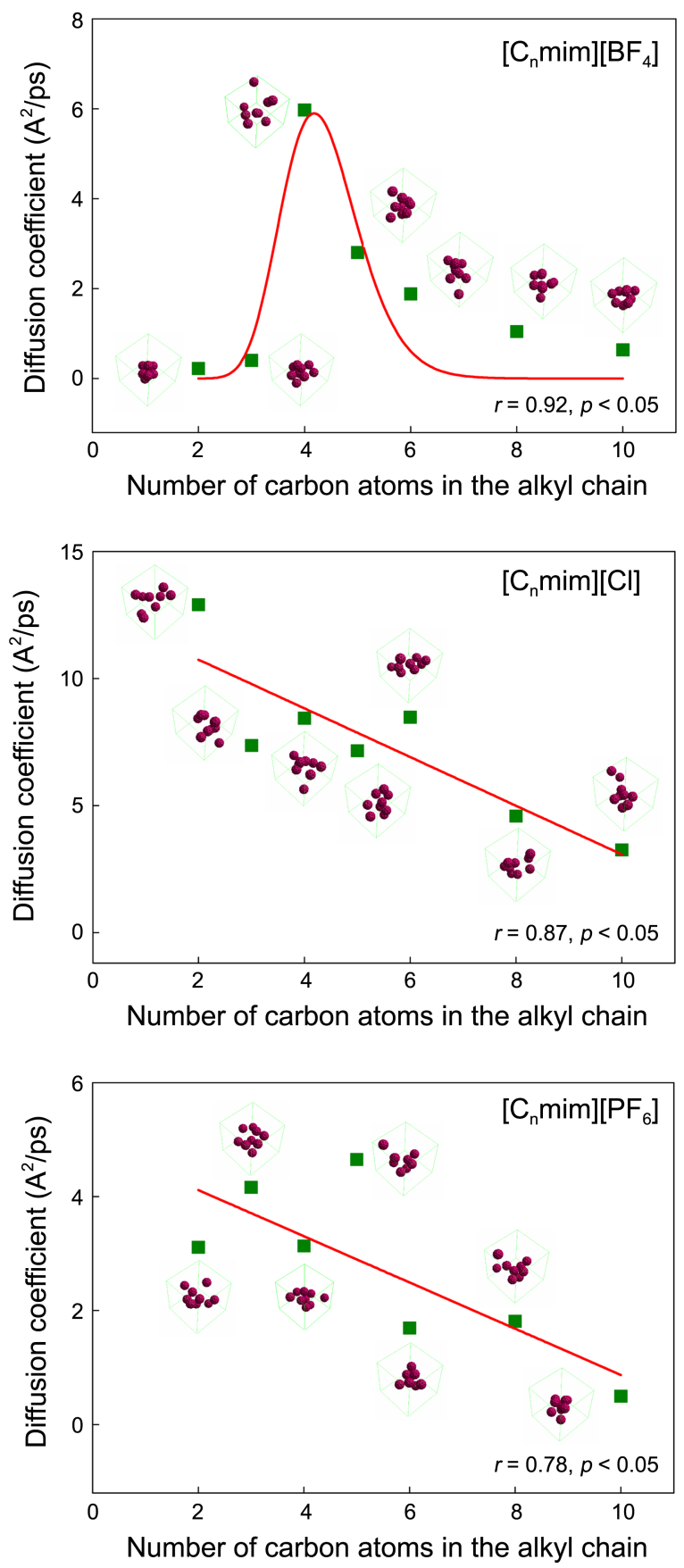

Figure 2. Diffusion coefficients of $\mathrm{C}_{60}$ as a function of the number of carbon atoms in the alkyl chain attached to the imidazolium ring. The insets are the perspective snapshots for the dispersion states of $\mathrm{C}_{60}$ in the different bulk ILs (not shown). ing $\left[\mathrm{BF}_{4}\right]^{-}$exhibits a different effect from the other two ILs containing $[\mathrm{Cl}]^{-}$and $\left[\mathrm{PF}_{6}\right]^{-}$. One can conclude that the anion may contribute to the effect. However, the anionic effect on the solubility of a solute is difficult to correlate. ${ }^{33}$ As aforementioned, the thermodynamic condition for the formation of the $\mathrm{C}_{60}-\left[\mathrm{C}_{\mathrm{n}} \mathrm{mim}\right]\left[\mathrm{BF}_{4}\right]$ complexes is also different from the $\mathrm{C}_{60}-\left[\mathrm{C}_{\mathrm{n}} \mathrm{mim}\right][\mathrm{Cl}]$ and $\mathrm{C}_{60}-\left[\mathrm{C}_{\mathrm{n}} \mathrm{mim}\right]\left[\mathrm{PF}_{6}\right]$ complexes. This implies that the thermodynamic property can play an important role in governing the effect of alkyl side chain length on

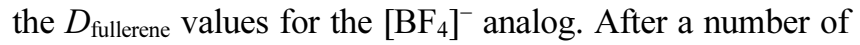
independent MD runs, note that ILs can influence the agglomeration behavior of $\mathrm{C}_{60}$ nanoparticles and cause their physical transformation. Thus we were able to expect that this finding may motivate new experimental studies on the assessment of ILs impacts on the environmental behavior of $\mathrm{C}_{60}$. Song et al. found that $\mathrm{C}_{60}$ nanoparticles with smaller size may have higher toxicity potency. As this study showed that ILs generally probe to disperse the $\mathrm{C}_{60}$ agglomerates, the presence of ILs may enhance the toxicity of $\mathrm{C}_{60}$ nanoparticles. $^{34}$

The PLS regression technique was used to find the fittest descriptors for developing the models of quantitative assessment of $D_{\text {fullerene }}$ (Eqs. (5)-(7)). Based on the $\mathrm{C}_{60}$-IL interactions, four interpretative descriptors $\left(H F, E_{\mathrm{INT}}, q\right.$ and $\left.n_{\mathrm{C}}\right)$ are tested during the development of the models. For $\mathrm{C}_{60}$ in the bulk $\left[\mathrm{C}_{\mathrm{n}} \mathrm{mim}\right]\left[\mathrm{BF}_{4}\right], H F$ and $n_{\mathrm{C}}$ are the most significant

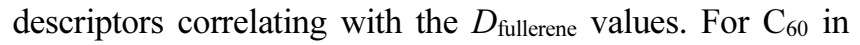
the bulk $\left[\mathrm{C}_{\mathrm{n}} \mathrm{mim}\right][\mathrm{Cl}], q$ and $n_{\mathrm{C}}$ are the most significant

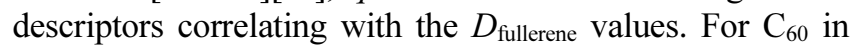
the bulk $\left[\mathrm{C}_{\mathrm{n}} \mathrm{mim}\right]\left[\mathrm{PF}_{6}\right], E_{\mathrm{INT}}$ and $n_{\mathrm{C}}$ are the most significant descriptors correlating with the $D_{\text {fullerene values. }}$

$$
\begin{aligned}
& \mathrm{C}_{60} \text { in }\left[\mathrm{C}_{\mathrm{n}} \operatorname{mim}\right]\left[\mathrm{BF}_{4}\right]: \\
& D_{\text {fullerene }}=-534.913-1.394 \cdot H F-7.715 \cdot n_{\mathrm{C}} \\
& n=7, r=0.918, R M S E=0.753, \mathrm{Q}^{2}{ }_{\mathrm{CUM}}=0.708 \\
& \mathrm{C}_{60} \text { in }\left[\mathrm{C}_{\mathrm{n}} \mathrm{mim}\right][\mathrm{Cl}]: \\
& D_{\text {fullerene }}=7.377-2.051 \times 10^{3} \cdot q-0.466 \cdot n_{\mathrm{C}} \\
& n=7, r=0.963, R M S E=0.524, \mathrm{Q}_{\mathrm{CUM}}^{2}=0.857 \\
& \mathrm{C}_{60} \text { in }\left[\mathrm{C}_{\mathrm{n}} \mathrm{mim}\right]\left[\mathrm{PF}_{6}\right]: \\
& D_{\text {fullerene }}=6.789-3.927 \times 10^{-2} \cdot E_{\mathrm{INT}}-0.620 \cdot n_{\mathrm{C}} \\
& n=7, r=0.903, R M S E=0.627, \mathrm{Q}_{\mathrm{CUM}}^{2}=0.592
\end{aligned}
$$

where $n$ stands for the number of ILs, $r$ is coefficient of correlation, RMSE is root mean squared error, and $\mathrm{Q}_{\mathrm{CUM}}^{2}$ is the cumulative percentage of variance explained for extracted components. $\mathrm{Q}_{\mathrm{CUM}}^{2}$ of the models are higher than 0.5, suggesting that their good robustness and internal predictability. Thus the models have high goodness-of-fit. The dispersion extent of $\mathrm{C}_{60}$ is related to three molecular descriptors ( $H F$, $E_{\mathrm{INT}}$, and $q$ ) that describe the $\mathrm{C}_{60}$-IL interactions. It is well known that within a particular family of chemical compounds (e.g. IL) that there are strong correlations between structure and observed properties. ${ }^{17,35}$ Thus, it is reasonable to believe that the molecular structural characteristics govern the $D_{\text {fullerene values. }}$ 


\section{Conclusion}

Through a detailed simulation at different theoretical levels (QM, MM, and classical MD), we have mainly addressed the dispersion mechanism of $\mathrm{C}_{60}$ agglomerates in the imidazolium-based ILs of varying the alkyl side chain lengths and anionic types. The IL-cation has a stronger interaction with $\mathrm{C}_{60}$ than its anionic partner. The formation of the $\mathrm{C}_{60}-\left[\mathrm{C}_{\mathrm{n}} \mathrm{mim}\right]\left[\mathrm{BF}_{4}\right]$ complexes is exothermic; the formation of the $\mathrm{C}_{60}-\left[\mathrm{C}_{\mathrm{n}} \mathrm{mim}\right][\mathrm{Cl}]$ and $\mathrm{C}_{60}-\left[\mathrm{C}_{\mathrm{n}} \mathrm{mim}\right]\left[\mathrm{PF}_{6}\right]$ complexes is endothermic; and $\mathrm{C}_{60}$ can form stable complex with each IL molecule. Furthermore, charge transfer occurred from IL to $\mathrm{C}_{60}$ during the $\mathrm{C}_{60}$-IL interaction. The models on $D_{\text {fullerene }}$ developed by PLS show high goodness-of-fit and robustness. Three molecular features $\left(H F, E_{\mathrm{INT}}\right.$, and $\left.q\right)$ that describe the $\mathrm{C}_{60}$-IL interaction and the alkyl side chain lengths attached to the imidazolium ring were found to be the decisive factors controlling $D_{\text {fullerene }}$.

Acknowledgments. The study was supported by the Project Funded by the Priority Academic Program Development of Jiangsu Higher Education Institutions (PAPD), the Foundation Research Project of Jiangsu Province (Grant No. BK20140987), and the Natural Science Key Research of Jiangsu Province High Education (Grant No. 11KJA170002). Degao Wang also thanks the support from "Open fund by Jiangsu Key Laboratory of Atmospheric Environment Monitoring and Pollution Control (Grant No. KHK1309)". We thank the reviewers for their valuable comments on the manuscript.

\section{References}

1. Petersen, E. J.; Zhang, L.; Mattison, N. T.; O'Carroll, D. M.; Whelton, A. J.; Uddin, N.; Nguyen, T.; Huang, Q.; Henry, T. B.; Holbrook, R. D.; Chen, K. L. Environ. Sci. Technol. 2011, 45, 9837.

2. Sanchis, J.; Berrojalbiz, N.; Caballero, G.; Dachs, J.; Farré, M.; Barceló, D. Environ. Sci. Technol. 2012, 46, 1335.

3. Cohen, Y.; Rallo, R.; Liu, R.; Liu, H. H. Acc. Chem. Res. 2013, 46,802 .

4. Klaine, S. J.; Koelmans, A. A.; Horne, N.; Carley, S.; Handy, R. D.; Kapustka, L.; Nowack, B.; von der Kammer, F. Environ. Toxicol. Chem. 2012, 31, 3.

5. Lowry, G. V.; Gregory, K. B.; Apte, S. C.; Lead, J. R. Environ. Sci. Technol. 2012, 46, 6893
6. Li, Q.; Xie, B.; Hwang, Y. S.; Xu, Y. Environ. Sci. Technol. 2009, $43,3574$.

7. Wang, L.; Huang, Y.; Kan, A. T.; Tomson, M. B.; Chen, W. Environ. Sci. Technol. 2012, 46, 5422.

8. Tummala, N. R.; Morrow, B. H.; Resasco, D. E.; Striolo, A. $A C S$ Nano 2010, 4, 7193.

9. Hou, L.; Zhu, D.; Wang, X.; Wang, L.; Zhang, C.; Chen, W. Environ. Toxicol. Chem. 2013, 32, 493.

10. Chang, X.; Vikesland, P. J. Environ. Pollut. 2009, 157, 1072.

11. Xie, B.; Xu, Z.; Guo, W.; Li, Q. Environ. Sci. Technol. 2008, 42, 2853.

12. Chen, K. L.; Elimelech, M. J. Colloid. Interface Sci. 2007, 309, 126.

13. Lin, S.; Blankschtein, D. J. Phys. Chem. B 2010, 114, 15616.

14. Li, D.; Lyon, D. Y.; Li, Q.; Alvarez, P. J. Environ. Toxicol. Chem. 2008, 27, 1888.

15. Binnemans, K. Chem. Rev. 2007, 107, 2592.

16. Pham, T. P.; Cho, C. W.; Yun, Y. S. Water Res. 2010, 44, 352.

17. Haumann, M.; Riisager, A. Chem. Rev. 2008, 108, 1474.

18. Wang, J.; Chu, H.; Li, Y. ACS Nano 2008, 2, 2540.

19. Gao, H.; Zhang, S.; Huang, D.; Zheng, L. Colloid. Polym. Sci. 2012, 290, 757 .

20. Maciel, C.; Fileti, E. E. Chem. Phys. Lett. 2013, 568-569, 75.

21. Ge, H. L.; Liu, S. S.; Zhu, X. W.; Liu, H. L.; Wang, L. J. Environ. Sci. Technol. 2011, 45, 1623.

22. Markiewicz, M.; Jungnickel, C.; Arp, H. P. Environ. Sci. Technol. 2013, 47, 6951 .

23. Zou, M.; Zhang, J.; Chen, J.; Li, X. Environ. Sci. Technol. 2012, $46,8887$.

24. Sun, Q.; Xie, H. B.; Chen, J.; Li, X.; Wang, Z.; Sheng, L. Chemosphere 2013, 92, 429.

25. Wang, Z.; Chen, J.; Sun, Q.; Peijnenburg, W. J. G. M. Environ. Int. 2011, 37, 1078

26. Westerhoff, P.; Nowack, B. Acc. Chem. Res. 2013, 46, 844.

27. Santos, S. G.; Santana, J. V.; Maia, F. F., Jr.; Lemos, V.; Freire, V. N.; Caetano, E. W.; Cavada, B. S.; Albuquerque, E. L. J. Phys. Chem. B 2008, 112, 14267.

28. Puzyn, T.; Rasulev, B.; Gajewicz, A.; Hu, X. K.; Dasari, T. P.; Michalkova, A.; Hwang, H. M.; Toropov, A.; Leszczynska, D.; Leszczynski, J. Nat. Nanotechnol. 2011, 6, 175 .

29. Pinkert, A.; Marsh, K. N.; Pang, S.; Staiger, M. P. Chem. Rev. 2009, 109, 6712 .

30. Yang, K.; Xing, B. Chem. Rev. 2010, 110, 5989.

31. Wang, Z.; Tang, L. L.; Peijnenburg, W. J. G. M. Environ. Toxicol. Chem. 2014, 33, 1802.

32. Wagle, D.; Kamath, G.; Baker, G. A. J. Phys. Chem. C 2013, 117, 4521.

33. Stark, A. Top. Curr. Chem. 2010, 290, 41.

34. Song, M.; Yuan, S.; Yin, J.; Wang, X.; Meng, Z.; Wang, H.; Jiang, G. Environ. Sci. Technol. 2012, 46, 3457.

35. Pádua, A. A.; Costa Gomes, M. F.; Canongia Lopes, J. N. Acc. Chem. Res. 2007, 40, 1087. 